\title{
A Nonselective Cyclooxygenase Inhibitor Enhances the Activity of Vinblastine in a Naturally-Occurring Canine Model of Invasive Urothelial Carcinoma
}

\author{
Deborah W. Knapp ${ }^{\text {a,b,*}}$, Audrey Ruple-Czerniak ${ }^{c}$, José A. Ramos-Vara ${ }^{\text {c }}$ James F. Naughton ${ }^{\text {, }}$ \\ Christopher M. Fulkerson ${ }^{\mathrm{a}}$ and Sonia I. Honkisz ${ }^{\mathrm{a}}$ \\ ${ }^{a}$ Department of Veterinary Clinical Sciences, Purdue University, West Lafayette, IN, USA \\ ${ }^{\mathrm{b}}$ Purdue University Center for Cancer Research, Purdue University, West Lafayette, IN, USA \\ ${ }^{\mathrm{c}}$ Department of Comparative Pathobiology, Purdue University, West Lafayette, IN, USA \\ ${ }^{\mathrm{d}}$ Indiana Veterinary Imaging, Indianapolis, IN, USA
}

\begin{abstract}
.
Background: Chemotherapy is expected to remain an important part of invasive urothelial carcinoma (UC) treatment. Strategies to enhance chemotherapy efficacy are needed.

Objective: To determine the chemotherapy-enhancing effects of a nonselective cyclooxygenase (COX) inhibitor on vinblastine in a naturally-occurring canine model of invasive UC.

Methods: With IACUC approval, privately-owned dogs with naturally-occurring histologically-diagnosed invasive UC, expected survival $\geq 6$ weeks, and informed owner consent were randomly allocated to receive vinblastine $\left(2.5 \mathrm{mg} / \mathrm{m}^{2} \mathrm{intra}-\right.$ venously every 2 weeks) plus piroxicam $(0.3 \mathrm{mg} / \mathrm{kg}$ daily per os) or vinblastine alone (same dose) with the option to receive piroxicam alone when vinblastine failed. Scheduled evaluations included physical exam, standard laboratory analyses, thoracic radiography, abdominal ultrasonography, and standardized measurement of urinary tract tumors.

Results: Dogs receiving vinblastine alone $(n=27)$ and vinblastine-piroxicam $(n=24)$ were similar in age, sex, breed, tumor stage, and grade. Remission occurred more frequently $(P<0.02)$ with vinblastine-piroxicam $(58.3 \%)$ than with vinblastine alone $(22.2 \%)$. The median progression free interval was 143 days with vinblastine alone and 199 days with the combination. Interestingly, the overall median survival time was significantly longer $(P<0.03)$ in dogs receiving vinblastine alone followed by piroxicam alone ( $n=20,531$ days) than in dogs receiving the combination (299 days). Treatment was well tolerated in both arms.

Conclusions: Piroxicam significantly enhanced the activity of vinblastine in dogs with UC where the cancer closely mimics the human condition, clearly justifying further study. The study suggest the potential importance of tracking COX inhibitor use in patients in clinical trials as COX inhibitors could affect treatment response.
\end{abstract}

Keywords: Urinary bladder cancer, transitional cell carcinoma, urothelial carcinoma, animal models, vinblastine, cyclooxygenase inhibitor, dog, piroxicam

\footnotetext{
*Correspondence to: Deborah W. Knapp, Purdue University, Dept. Veterinary Clinical Sciences, 625 Harrison St., West
} 


\section{INTRODUCTION}

There were an estimated 16,000 human deaths from urinary bladder cancer in the United States in 2015 [1]. Clearly, more effective therapies are needed. Chemotherapy is a mainstay in the treatment for muscle invasive bladder cancer, specifically invasive urothelial carcinoma (UC) [2-5]. Chemotherapy is applied in the neoadjuvant and adjuvant setting in patients undergoing cystectomy, in bladdersparing treatment approaches, and in the treatment of detected metastases [2-5]. As targeted drugs and immunotherapies for bladder cancer are developed [6-11], it is likely that chemotherapy will be included in combination protocols with these newer agents. Chemotherapeutic drugs used to treat patients with UC have typically included cisplatin, carboplatin, vinblastine, paclitaxel, and gemcitabine [2-4]. Although these drugs have well-documented antitumor effects, strategies to improve their activity and to prevent or delay subsequent resistance are crucial.

Cyclooxygenase (COX) inhibitors have been investigated for chemopreventive activity in reducing the occurrence of bladder cancer [12-23], for antitumor effects against established bladder cancer [14, 15, 24-37], and for effects in enhancing chemotherapy [24, 26, 28-30, 38], with positive results in most, but not all studies. Several mechanisms of the antitumor activity of COX inhibitors have been proposed including direct induction of apoptosis [27, 38, 39], immunomodulatory effects $[25,24,40]$, antiangiogenic activity [40], changes in microRNAs [41], and inhibitory effects on cancer stem cells [37]. Studies have been performed in rodents with experimentally-induced bladder tumors [12-15, 24, 37], in humans in epidemiological and clinical studies [16-23, 35, 36, 38], and in dogs with naturally-occurring UC (high grade invasive urothelial carcinoma or transitional cell carcinoma) [25-34]. UC in dogs closely mimics invasive bladder cancer in humans with regards to cellular and molecular characteristics including COX-2 expression, local cancer invasion, distant metastases, and response to chemotherapy [42]. In dogs with UC, COX inhibitors have had activity as single agents in inducing remission (20\% remission rate) and stable disease (55\% stable disease rate), and enhancing the activity of platinum chemotherapy, especially cisplatin [25-31]. Across multiple studies in dogs with UC, the remission rate has been approximately $20 \%$ with single agent cisplatin and $50-70 \%$ when cisplatin is combined with a COX inhibitor $[26,28,30]$. There is considerable interest in determining if COX inhibitors will enhance the effects of other chemotherapeutic agents, especially given the fact that many patients are considered unfit for cisplatin treatment.

The purpose of this study was to determine the effects of a nonselective COX inhibitor (piroxicam) in enhancing the antitumor activity of vinblastine in dogs with UC. Vinblastine was selected because of its activity against UC in dogs and humans and good safety profile $[4,43,44]$. There are also recent reports of combining vinblastine and COX inhibitors in other cancers $[45,46]$.

\section{MATERIALS AND METHODS}

\section{Study overview}

This study was approved by and performed following the guidelines and approval of the Purdue Animal Care and Use Committee. A randomized treatment trial was conducted in privately-owned pet dogs with naturally-occurring invasive UC. The participating dogs had been presented to the Purdue University Veterinary Teaching Hospital (PUVTH) for evaluation and treatment, and their owner elected to enroll them in the trial. The dogs were randomly allocated to receive vinblastine alone or vinblastine combined with the nonselective COX inhibitor, piroxicam. Other than the days of vinblastine treatment and evaluation, the dogs lived at home with their owners.

\section{Entry criteria}

Entry criteria included: histopathologic diagnosis of invasive UC (biopsy samples collected at surgery or cystoscopy), measurable cancer in the bladder and/or urethra, expected survival of at least 6 weeks, informed dog owner consent in writing, no prior vinca alkaloid treatment, and no prior COX inhibitor treatment in the previous six months that had lasted more than two weeks. If the dog had received any COX inhibitor in the previous week, a minimum washout period was required consisting of 5 days for piroxicam (due to its extended half-life), and 3 days for other COX inhibitors. Dogs with metastases (detected by radiography, ultrasonography, or CT), as well as those with organ confirmed UC, were eligible to enroll in the study. 


\section{Dog evaluation}

Evaluation of the dogs before and during treatment included: physical exam including rectal exam and complete blood count (CBC) weekly; serum biochemical profile, urinalysis, and urinary tract ultrasound every four weeks; and thoracic radiography (ventral-dorsal, left lateral, and right lateral projections) and complete abdominal ultrasound every eight weeks to detect and measure metastases. A detailed ultrasound mapping protocol of the urinary tract was used in which the ultrasound machine, operator, dog position, imaging plane, and degree of bladder distension were standardized across all visits [47]. This technique has been found to produce less than $10 \%$ variability in repeated measurements of individual lesions on the same day (unpublished data, Honkisz, Naughton, \& Knapp). Images were interpreted by a board certified veterinary radiologist (JFN) who was blinded to treatment group. Tumor stage was classified following WHO criteria [48]. Available pathology slides from diagnosis were reviewed by one pathologist (JAR-V). Permission to perform a necropsy was requested when the dogs died or were euthanized due to cancer-related or noncancer-related causes.

\section{Treatment}

Dogs were randomly allocated to receive either vinblastine alone or vinblastine combined with piroxicam. Vinblastine (APP Pharmaceuticals LLC, Schaumburg, IL) was administered at a dosage of $2.5 \mathrm{mg} / \mathrm{m}^{2}$ intravenously every two weeks to $\operatorname{dogs}$ weighing $\geq 15 \mathrm{~kg}$, and at a dosage of $2 \mathrm{mg} / \mathrm{m}^{2}$ intravenously every two weeks to dogs weighing $<15 \mathrm{~kg}$. Body surface area dosing of chemotherapy in dogs results in overexposure in very small dogs, and therefore, doses are adjusted for body size [49]. Piroxicam (Piroxicam USP, Pure Powder, PCCA, Houston, TX) was compounded into capsules in the PUVTH Pharmacy and given at a dosage of $0.3 \mathrm{mg} / \mathrm{kg}$ daily by mouth with food. Dogs who had cancer progression when receiving vinblastine alone were eligible to receive piroxicam alone or to go off study and receive different therapy. Dogs failing vinblastine and piroxicam (combined or sequentially) were eligible to receive other treatments off study.

When dose limiting toxicity (Veterinary Cooperative Oncology Group criteria [50]) was encountered, the vinblastine treatment was delayed by one week, and the dose was reduced by $10 \%$ for grade 2 toxicity, and by $20 \%$ for grade 3 or 4 toxicity. If gastrointestinal upset occurred that was attributed to piroxicam, piroxicam was withdrawn for 3-5 days (or until clinical signs resolved), and then a selective COX-2 inhibitor, deracoxib (Deramaxx, Novartis, Greensborough, NC; $3 \mathrm{mg} / \mathrm{kg}$ daily), was substituted for piroxicam. If worsening azotemia occurred that was considered unrelated to the cancer or secondary urinary tract infection, and possibly due to piroxicam, then piroxicam was stopped, and deracoxib instituted 3-5 days later.

\section{Response criteria}

The response of cancer lesions within the urinary tract was classified using volume measurements as follows: complete remission (CR, complete resolution of all evidence of cancer), partial remission (PR, $\geq 50 \%$ reduction in tumor volume and no new tumor lesions, stable disease (SD, $<50 \%$ change in tumor volume and no new tumor lesions), and progressive disease (PD, $\geq 50 \%$ increase in tumor volume or new tumor lesions). The response of cancer lesions outside of the urinary tract was classified using RECIST criteria [51].

\section{Sample size calculation and statistical methods}

The primary endpoint was the percentage of dogs attaining remission in each treatment group. Based on the expected remission rate in the single agent treatment arm of $30 \%$, and the aim to detect a doubling of the remission rate (i.e. $60 \%$ remission rate in the combination treatment arm), it was calculated that a minimum of 22 dogs were needed per treatment group using a power of 0.8 , and $P<0.05$ being statistically significant. Frequency distributions of categorical variables were evaluated using Pearson Chi-square test or Fisher's exact test depending upon the cell size and number of groups recorded for each variable. The Shapiro-Wilk statistic was used to assess normality of distribution of continuous variables and nonparametric tests were used for statistical analysis. The two treatment groups were tested for differences in sex/neuter status, age, weight, level of breedassociated risk for developing TCC, tumor, TNM stage, presence of metastases at the time of diagnosis, urethral or prostate involvement, hematologic and gastrointestinal toxicity, tumor response, time to disease progression, and overall survival time. Predetermined secondary endpoints were progression free 
interval (PFI, time from the start of vinblastine until PD occurred), survival (time from first vinblastine treatment until death), and treatment related toxicity. A $P$-value of $<0.05$ was considered significant for all statistical analyses.

\section{RESULTS}

A total of 58 dogs were evaluated for the study, and 51 dogs met the eligibility criteria for enrollment and were randomly allocated into treatment groups. No statistically significant differences were detected between treatment groups with regards to sex/neuter status, age, weight, level of breed-associated risk for developing UC, tumor grade, TNM stage, presence of metastases at the time of diagnosis, or urethral or prostate involvement (Table 1). Dogs receiving vinblastine and piroxicam simultaneously had a better response rate with 14 of 24 dogs (58.3\%) achieving remission as compared to 6 of $27 \mathrm{dogs}(22.2 \%)$ receiving vinblastine alone $(P=0.02)$ (Table 2). All remissions were partial; complete remission was not observed. Of the 27 dogs that received vinblastine alone, the owners of $20 \mathrm{dogs}$ elected to have their dog treated with piroxicam alone when cancer progression occurred on vinblastine. The tumor response to piroxicam alone in these 20 dogs included PR in 3 dogs, SD in 9 dogs, and PD in 5 dogs; tumor response could not be assessed in 3 dogs.

The median PFI and survival times for dogs receiving vinblastine alone were 143 and 407 days, respectively (Figs. 1 and 2). The median PFI and survival times for dogs receiving vinblastine and piroxicam were 199 and 299 days, respectively (Figs. 1 and 2). Interestingly, the median overall survival time for dogs receiving vinblastine alone followed by piroxicam alone ( $n=20,531$ days) was significantly longer $(P=0.03)$ compared to dogs receiving vinblastine and piroxicam simultaneously (299 days) (Fig. 3). No statistically significant differences were detected between these groups of 20 and

Table 1

Subject characteristics of dogs participating in the clinical trial

\begin{tabular}{lcc}
\hline Characteristic & $\begin{array}{c}\text { Vinblastine } \\
\text { alone } n=27\end{array}$ & $\begin{array}{c}\text { Vinblastine-piroxicam } \\
n=24\end{array}$ \\
\hline Age at diagnosis, years, median (range) & $10.9(5.3-15.2)$ & $11.6(8.8-15.3)$ \\
Sex and neuter status & & $15(62.5 \%)$ \\
Female spayed & $14(51.9 \%)$ & $9(37.5 \%)$ \\
Male neutered & $13(48.2 \%)$ & $10(41.7 \%)$ \\
Breed* & & $7(29 \%)$ \\
At-risk breed dogs [42] & $9(333 \%)$ & $7(29 \%)$ \\
Other pure-bred dogs & $12(44 \%)$ & $15.5(4.1-35.0)$ \\
Mixed breed dogs & $6(22 \%)$ & \\
Weight, kgs, median (range) & $13.0(4.0-46.3)$ & $2(8.3 \%)$ \\
Tumor grade [42] & & $19(79.2 \%)$ \\
Intermediate & $4(14.8 \%)$ & $3(12.5 \%)$ \\
High & $21(77.8 \%)$ & $18(75.0 \%)$ \\
Slide not available for review of grade & $2(7.4 \%)$ & $6(25.0 \%)$ \\
WHO stage, as defined for canine bladder cancer [48] & & 0.680 \\
T2, tumor invading bladder wall with induration & $21(77.8 \%)$ & 0.697 \\
T3, tumor invading neighboring organs & $6(22.2 \%)$ & 0.575 \\
(prostate, uterus, vagina, pelvic canal) & & $24(100.0 \%)$ \\
N0 (No nodal metastases) & $26(96.3 \%)$ & 0 \\
N1 (Nodal metastases present) & $1(3.7 \%)$ & $23(95.8 \%)$ \\
M0 (No distant metastases) & $25(92.6 \%)$ & $1(4.2 \%)$ \\
M1 (Distant metastases present) & $2(7.4 \%)$ & $1(4.2 \%)$ \\
Any metastases present & $3(11.1 \%)$ & $17(70.8 \%)$ \\
Urethral involvement & $13(48.2 \%)$ & 0.537 \\
Prostate involvement & $(53.8 \%)$ & $(55.6 \%)$ \\
& of $13 \%$ male & 0.529 \\
\hline
\end{tabular}

*The breeds of dogs receiving vinblastine alone included 6 mixed breed dogs, 4 Scottish terriers, 2 West Highland White Terriers, 2 Shetland Sheepdogs, 2 Miniature Schnauzers, 2 Yorkshire Terriers, 2 Pembroke Welsh Corgis, and 1 each of the following breeds: Beagle, Dachshund, Boston Terrier, English Springer Spaniel, Tibetan Terrier, Maltese, and German Shepherd. The breeds of dogs receiving combined vinblastine and piroxicam included 7 mixed breed dogs, 3 West Highland White Terriers, 3 Beagles, 2 Shetland Sheepdogs, 2 Australian Shepherds, and 1 each of the following breeds: Scottish Terrier, Dachshund, Treeing Walker Coonhound, Labrador Retriever, Airedale Terrier, American Cocker Spaniel, and Basset Hound. 
Table 2

Tumor response in dogs in the clinical trial

\begin{tabular}{|c|c|c|c|}
\hline & $\begin{array}{c}\text { Vinblastine alone } \\
n=27\end{array}$ & $\begin{array}{c}\text { Vinblastine-piroxicam } \\
n=24\end{array}$ & $P$-value \\
\hline \multicolumn{4}{|l|}{ Tumor response, number of dogs (\%) } \\
\hline Complete remission & $0(0.0 \%)$ & $0(0.0 \%)$ & 0.019 \\
\hline Partial remission & $6(22.2 \%)$ & $14(58.3 \%)$ & \\
\hline Stable disease & $19(70.4 \%)$ & $8(33.3 \%)$ & \\
\hline Progressive disease & $1(3.7 \%)$ & $2(8.3 \%)$ & \\
\hline Not evaluable & $1(3.7 \%)$ & $0(0.0)$ & \\
\hline Progression free interval, days, median (range) & $143(1-1015)$ & $199(21-593)$ & 0.128 \\
\hline Survival, days, median (range) & $407(13-1132)$ & $299(21-637)$ & 0.668 \\
\hline
\end{tabular}

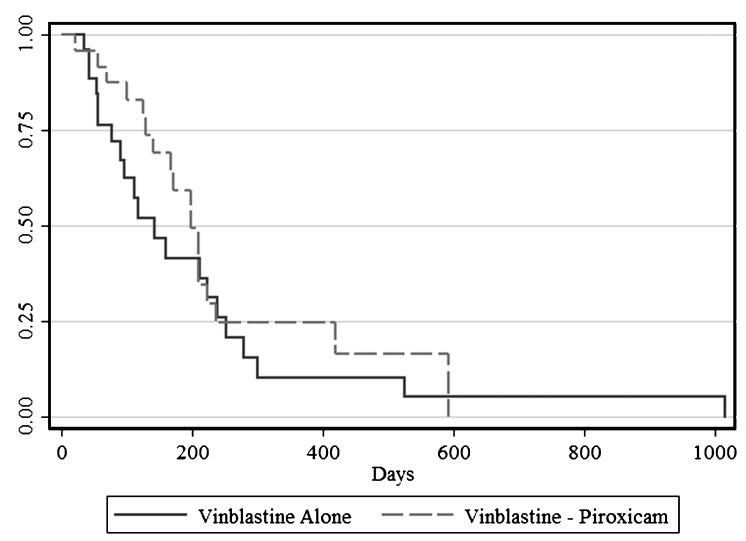

Fig. 1. Progression free interval (PFI) for dogs receiving vinblastine alone and dogs receiving vinblastine and piroxicam simultaneously. The median PFI was 143 days in dogs receiving vinblastine alone and 199 days in dogs receiving the combination treatment $(P=0.128)$.

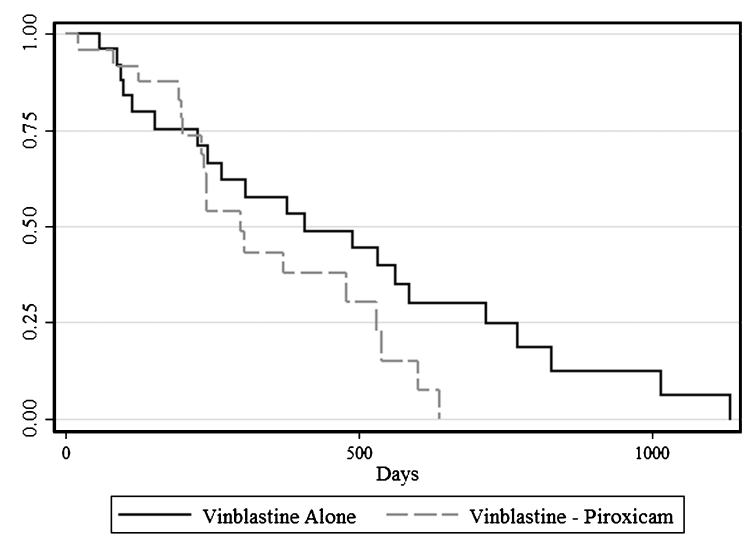

Fig. 2. Overall survival of dogs receiving vinblastine alone and dogs receiving vinblastine and piroxicam simultaneously. The median survival was 407 days in dogs initially treated with vinblastine alone and 299 days in dogs receiving the combination treatment $(P=0.668)$.

24 dogs in regards to subject or tumor characteristics and other therapies given after the study drugs had failed. No statistically significant differences were



Fig. 3. Overall survival of dogs receiving vinblastine and piroxicam simultaneously $(n=24)$ and dogs receiving vinblastine alone followed by piroxicam alone $(n=20)$. The median survival time for dogs receiving vinblastine alone followed by piroxicam alone (531 days) was significantly longer $(P=0.03)$ than the survival of dogs receiving vinblastine and piroxicam simultaneously (299 days). The tumor and subject characteristics and the administration of other therapies after the study drugs had failed were similar between the two groups.

detected in the frequency of hematologic or gastrointestinal toxicities between treatment groups (Table 3).

In both treatment groups, when the cancer became resistant to vinblastine and piroxicam, and cancer progression was noted, the dogs were allowed to receive additional treatment off study. Of the $27 \mathrm{dogs}$ initially receiving vinblastine alone, 12 dogs (44.4\%) received one or more additional chemotherapy drugs including mitoxantrone in $10 \mathrm{dogs}$, metronomic chlorambucil in 3 dogs, carboplatin in 2 dogs, a demethylating agent (zebularine) in 2 dogs, gemcitabine in $1 \mathrm{dog}$, and mitomycin $\mathrm{C}$ in $1 \mathrm{dog}$. Of the 24 dogs initially treated with vinblastine and piroxicam combined, $15(62.5 \%)$ of the dogs went on to receive one or more other chemotherapy drugs after failing vinblastine and piroxicam. These drugs included mitoxantrone in 9 dogs, metronomic chlorambucil in 7 dogs, zebularine in 4 dogs, carboplatin 
Table 3

Treatment related toxicity (Veterinary Cooperative Oncology Group criteria) [50] in dogs in the clinical trial

\begin{tabular}{|c|c|c|c|}
\hline & $\begin{array}{c}\text { Vinblastine } \\
\text { alone } n=27\end{array}$ & $\begin{array}{c}\text { Vinblastine- } \\
\text { piroxicam } n=24\end{array}$ & $P$-value \\
\hline \multicolumn{4}{|c|}{$\begin{array}{l}\text { Hematologic toxicity, } \\
\text { number of dogs }(\%)\end{array}$} \\
\hline 0 & $14(51.9 \%)$ & $17(70.8 \%)$ & 0.541 \\
\hline 1 & $7(25.9 \%)$ & $2(8.3 \%)$ & \\
\hline 2 & $2(7.4 \%)$ & $2(8.3 \%)$ & \\
\hline 3 & $1(3.7 \%)$ & $1(4.2 \%)$ & \\
\hline 4 & $3(11.1 \%)$ & $2(8.3 \%)$ & \\
\hline \multicolumn{4}{|c|}{$\begin{array}{c}\text { Gastrointestinal toxicity, } \\
\text { number of dogs }(\%)\end{array}$} \\
\hline 0 & $22(81.5 \%)$ & $19(79.2 \%)$ & 0.562 \\
\hline 1 & $4(14.8 \%)$ & $2(8.3 \%)$ & \\
\hline 2 & $1(3.7 \%)$ & $2(8.3 \%)$ & \\
\hline 3 & $0(0.0 \%)$ & $1(4.2 \%)$ & \\
\hline 4 & $0(0.0 \%)$ & $0(0.0 \%)$ & \\
\hline
\end{tabular}

in 2 dogs, and the following drugs in one dog each: folate-vinblastine, folate-tubulysin, toceranib phosphate, and mitomycin C.

\section{DISCUSSION}

In this study, piroxicam significantly enhanced the antitumor activity of vinblastine in dogs with UC. Partial remission was detected in $58 \%$ of dogs receiving the combination compared to $22 \%$ of dogs receiving vinblastine alone. The drugs were well tolerated in both treatment arms, as is essential for studies in pet animals. The findings were consistent with previous studies in dogs with UC in which nonselective COX inhibitors and more selective COX-2 inhibitors had notable activity in enhancing the activity of cisplatin and carboplatin [26, 28-30]. In fact, COX inhibitors are commonly included in the routine treatment of pet dogs with UC, either as single agents or in combination with chemotherapy [25-34, 42]. Similar chemotherapy enhancing effects of COX inhibitors have been reported in rodents with experimentally induced bladder tumors [24, 37].

Another intriguing finding from the study was that dogs that initially received single agent vinblastine and then single agent piroxicam lived significantly longer than those receiving combination vinblastine and piroxicam. The treatments given after failure of the study drugs were similar across the groups. This longer survival was not entirely unexpected as survival appeared longer for dogs sequentially receiving platinum chemotherapy alone followed by a COX inhibitor alone than for dogs receiving the drugs concurrently in two earlier studies in dogs $[26,30]$. The reason for this is not known, but could be due to the development of resistance to both drugs at the same time when the drugs were given concurrently, rather than developing resistance to each drug separately over a longer period of time when the drugs were given sequentially. It is also possible that the chemotherapy could in some way sensitize the tumor or allow selection of clones of tumor cells within the tumor that would then respond to subsequent COX inhibitor treatment. Selection bias was not thought to be involved as all the dogs receiving vinblastine alone were eligible to subsequently receive piroxicam alone or to receive different therapies according to the wishes of the pet owner, and the severity of the cancer did not appear to differ between dogs receiving piroxicam alone and dogs receiving other management, although further study would be needed to confirm this.

It is important to note the similarities between canine and human UC when considering the likelihood that the results of this canine study could be recapitulated in human studies. UC between dogs and humans is similar in cellular and molecular characteristics, physiological age at diagnosis, presenting clinical signs, local invasion, the development of distant metastases in approximately $50 \%$ of cases, and response to chemotherapy $[42,52,53]$. One recently defined difference between UC in dogs and humans is that canine UC commonly harbors a specific mutation in the BRAF gene in the MAP kinase signaling pathway [54, 55]. Specifically, canine UC frequently expresses the dog homologue of the BRAF V600E mutation that is reported to be important in $8 \%$ of all human cancer [54-56]. Although BRAF mutations are rare in human UC, variants in associated signaling pathways have been reported in humans [57]. Even with the presence of the BRAF V600E mutation in canine $\mathrm{UC}$, expression array studies continue to demonstrate many similarities between the cancer in humans and dogs [53]. With this close resemblance between naturally-occurring UC in dogs and humans, and the findings of the chemotherapy-enhancing effects of a COX inhibitor, there is compelling justification to investigate this approach in humans with UC. Chemotherapy is expected to remain an integral part of the treatment of UC even as more targeted agents and immunotherapies are developed.

With the effects of piroxicam-enhancing the activity of vinblastine in dogs, and similar chemotherapyenhancing effects of COX inhibitors reported in other animals studies [24, 26-30,37], it would appear likely that such additive or synergistic drug activity could 
occur in humans with UC. This raises an important consideration. When human patients in clinical trials take COX inhibitors, with or without their physician's recommendation or knowledge, it could affect how well their cancer responds to treatment. Should this be the case, it would be essential to track and record COX inhibitor use in patients in clinical trials and to factor in that information when interpreting results.

There are multiple possible mechanisms by which COX inhibitors could enhance the activity of chemotherapy. Chronic inflammatory changes associated with cancer can lead to evasion of apoptosis, enhanced invasion and metastasis, increased angiogenesis, and increased infiltration by immunosuppressive cells, and COX inhibitors could block or potentially reverse these changes [24, 40]. Other proposed mechanisms of COX inhibitor antitumor effects include: inhibiting the prostaglandin $\mathrm{E}_{2}$ induced repopulation of cancer stem cells that occurs during chemotherapy [37], restoring chemosensitivity through modulation of microRNA expression [41], and blocking drug transporters involved in multidrug resistance [58], a mechanism of importance in vinblastine resistance [59]. Whether through direct or indirect mechanisms, a consistent finding across studies is induction of apoptosis in cancer cells following COX inhibitor treatment $[12,27,39,60]$. This finding was previously reported in humans with UC who were treated with celecoxib during the time between transurethral resection and cystectomy [38].

With the emergence of immune checkpoint inhibitors in cancer therapy [61], it is intriguing to consider the potential beneficial effects of combining COX inhibitors with these newer agents. COX-2 products can have several deleterious effects on the immune response to cancer including augmentation of pro-tumorigenic type 2 macrophages, inhibition of NK cell migration and function, reduced maturation of dendritic cells and MHC class II expression, inhibition $\mathrm{T}$ and $\mathrm{B}$ lymphocyte proliferation, induction of regulatory $\mathrm{T}$ cells, and enhanced and maintained numbers of myeloid derived suppressor cells [62]. Even if immune checkpoints are inhibited, the deleterious processes put into effect by COX products can still prevent an effective immune attack against the cancer. The use of COX inhibitors to prevent or reverse these deleterious effects would be expected to enhance the beneficial effects of immune checkpoint inhibitors. There is, in fact, evidence for this as aspirin has been found to enhance the activity of an anti-PD-1 antibody in mice with melanomas [63]. In other experimental settings, however, chronic
COX inhibitor administration was associated with increased expression of the immune checkpoint, PD-1 [64].

The antitumor effects of COX inhibitors have been reported to include those dependent on the inhibition of COX-2 as well as COX-2 independent effects [61-66]. It is not currently known whether nonselective COX inhibitors or COX-2 specific inhibitors offer the greatest advantages in cancer patients. From a safety perspective, COX-2 inhibitors offer less risk of gastrointestinal irritation when compared to nonselective COX inhibitors [65], but concerns persist for the cardiovascular risk of selective COX-2 inhibitors $[66,67]$. The nonselective COX inhibitor, piroxicam, was included in the current study because of its impressive activity in previous trials in dogs with UC [25-28, 42]. Piroxicam is commonly included in the treatment of UC in dogs due its antitumor activity as well as its notable effects on improving quality of life for the dog [42]. Vinblastine was selected for this study because it has good antitumor activity and safety profile in dogs and humans with UC, and it is currently in use in treatment protocols in both species $[4,43,44]$.

In the current study, vinblastine and piroxicam were given as frontline therapy, thus the cancer had not developed resistance which could occur during the course of other therapies. A noted opportunity in dog studies is that there is not a defined and mandated standard of care treatment that must be followed in each dog, thus a new treatment which is expected to be safe and have good activity can be tested in a frontline setting. By enrolling dogs soon after diagnosis, most of the dogs in the current study had cancer which, based on detection with radiography and ultrasonography, was confined to the urinary tract. The expectation would be that the chemotherapy-enhancing effects of COX inhibitors would apply in the metastatic setting, but the overall antitumor activity would likely be less pronounced, although further work would be needed to confirm this. When interpreting the results of this study, another aspect of the management of dog bladder cancer should be taken into consideration. Cystectomy is rarely performed in pet dogs, and it was not performed in any of the dogs in the study. Cystectomy is not performed in pet dogs with UC because of the frequency of trigonal lesions that extend down the urethra making surgical cure less likely, and because the morbidity and costs associated with the procedure are not acceptable to most pet owners. With the primary tumor left intact, the opportunity for metastasis continues through the treatment period. 
When considering how to optimize the chemotherapy-enhancing effects of COX inhibitors, further study is needed to confirm that the effects observed with a single agent chemotherapy protocol would apply to protocols that include multiple chemotherapeutic agents. The interplay between multiple agents could be important. If a patient's health is compromised during dose intense protocols involving multiple chemotherapeutic agents, it is possible that the response to the COX inhibitor could be different than in more conservative treatment regimens. The intensity of the COX inhibitor treatment itself is another variable to be studied. In recent rodent studies, the intermittent administration of COX inhibitors, which would be expected to cause less gastric irritation in humans, still provided good antitumor activity [12].

In conclusion, the nonselective COX inhibitor, piroxicam, enhanced the activity of vinblastine in dogs with UC where the cancer closely mimics the human condition. In previous studies in dogs with UC, COX inhibitors also enhanced the activity of cisplatin and carboplatin. With the close similarities between naturally-occurring UC in dogs and UC in humans, it is expected that COX inhibitors could also enhance the activity of chemotherapy in humans with this cancer. There is compelling justification to evaluate combination therapies that include chemotherapy and COX inhibitors in humans. In trials of new drugs in humans with UC that do not formally include a COX inhibitor, it may still be very important to track the use of COX inhibitors in the patients in the trials because of potential effects on their treatment response.

\section{ACKNOWLEDGMENTS}

Funding: The study was supported by private donations made to Purdue University for bladder cancer research.

The authors would like to thank the staff and clinicians of the Purdue Comparative Oncology Program for assisting with the work in the clinical trial, and to additionally thank Chris Royce, RVT; Lindsey Fourez, BS, RVT; and Patty Bonney, BS, RVT for data management. The authors also thank the families of the participating dogs for making this trial successful.

\section{CONFLICTS OF INTEREST}

The authors have no conflict of interest to report.

\section{REFERENCES}

[1] Siegel, R., Miller, K, Jemal, A. Cancer statistics, 2015. CA Cancer J Clin 2015;65:5-29.

[2] Raghavan D. Chemotherapy for Invasive bladder cancer: Five simple rules learned over 30 years. Bladder Cancer 2015;1(1):3-13.

[3] Knollman H, Godwin JL, Jain R, Wong YN, Plimack ER, Geynisman DM. Muscle-invasive urothelial bladder cancer: An update on systemic therapy. Ther Adv Urol 2015;7(6):312-30.

[4] Choueiri TK, Jacobus S, Bellmunt J, Qu A, Appleman LJ, Tretter C, Bubley GJ, Stack EC, Signoretti S, Walsh M, Steele G, Hirsch M, Sweeney CJ, Taplin ME, Kibel AS, Krajewski KM, Kantoff PW, Ross RW, Rosenberg JE. Neoadjuvant dose-dense methotrexate, vinblastine, doxorubicin, and cisplatin with pegfilgrastim support in muscle-invasive urothelial cancer: Pathologic, radiologic, and biomarker correlates. J Clin Oncol 2014;32(18):1889-94.

[5] Arcangeli G, Strigari L, Arcangeli S. Radical cystectomy versus organ-sparing trimodality treatment in muscleinvasive bladder cancer: A systematic review of clinical trials. Crit Rev Oncol Hematol 2015;95(3):387-96.

[6] Mitra AP, Lerner SP. Potential role for targeted therapy in muscle-invasive bladder cancer: Lessons from the cancer genome atlas and beyond. Urol Clin North Am 2015;42(2):201-15.

[7] Apolo AB, Vogelzang NJ, Theodorescu D. New and promising strategies in the management of bladder cancer. Am Soc Clin Oncol Educ Book 2015:105-12.

[8] Cancer Genome Atlas Research Network. Comprehensive molecular characterization of urothelial bladder carcinoma. Nature 2014;507(7492):315-22.

[9] Rouanne M, Loriot Y, Lebret T, Soria JC. Novel therapeutic targets in advanced urothelial carcinoma. Crit Rev Oncol Hematol 2015, Nov 9. pii: S1040-8428(15)30070-6. doi: 10.1016/j.critrevonc.2015.10.021. [Epub ahead of print]

[10] Philips GK, Atkins M. Therapeutic uses of anti-PD-1 and anti-PD-L1 antibodies. Int Immunol 2015;27(1):39-46.

[11] Carosella ED, Ploussard G, LeMaoult J, Desgrandchamps F. A systematic review of immunotherapy in urologic cancer: Evolving roles for targeting of CTLA-4, PD-1/PD-L1, and HLA-G. European Urology 2015;26(2):267-79.

[12] Lubet RA, Scheiman JM, Bode A, White J, Minasian L, Juliana MM, Boring DL, Steele VE, Grubbs CJ. Prevention of chemically induced urinary bladder cancers by naproxen: Protocols to reduce gastric toxicity in humans do not alter preventive efficacy. Cancer Prev Res (Phila) 2015;8(4):296302.

[13] Fischer SM, Hawk ET, Lubet RA. Coxibs and other nonsteroidal anti-inflammatory drugs in animal models of cancer chemoprevention. Cancer Prev Res (Phila) 2011;4(11):1728-35.

[14] Sereno J, Parada B, Reis F, Cunha FX, Teixeira-Lemos E, Garrido P, Pinto R, Rocha-Pereira P, Neto P, Ruivo J, Rodrigues-Santos P, Nunes S, Mota A, Figueiredo A, Teixeira F. Preventive but not curative efficacy of celecoxib on bladder carcinogenesis in a rat model. Mediators Inflamm 2010;2010:380937.

[15] Nicastro HL1, Grubbs CJ, Margaret Juliana M, Bode AM, Kim MS, Lu Y, You M, Milne GL, Boring D, Steele VE, Lubet RA. Preventive effects of NSAIDs, NO-NSAIDs, and NSAIDs plus difluoromethylornithine in a chemically induced urinary bladder cancer model. Cancer Prev Res (Phila) 2014;7(2):246-54. 
[16] Ou SM, Chen YT, Chao PW, Lee YJ, Liu CJ, Yeh CM, Chen TJ, Chen TW, Yang WC, Li SY. Nonsteroidal anti-inflammatory drug use is associated with cancer risk reduction in chronic dialysis patients. Kidney Int 2013; 84(1):198-205.

[17] Pastore A, Palleschi G, Fuschi A, Silvestri L, Al Salhi Y, Costantini E, Zucchi A, Petrozza V, de Nunzio C, Carbone A. Can daily intake of aspirin and/or statins influence the behavior of non-muscle invasive bladder cancer? A retrospective study on a cohort of patients undergoing transurethral bladder resection. BMC Cancer 2015;15:120.

[18] Castelao JE1, Yuan JM, Gago-Dominguez M, Yu MC, Ross RK. Non-steroidal anti-inflammatory drugs and bladder cancer prevention. Br J Cancer 2000;82(7):1364-69.

[19] Fortuny J, Kogevinas M, Zens MS, Schned A, Andrew AS, Heaney J, Kelsey KT, Karagas MR. Analgesic and anti-inflammatory drug use and risk of bladder cancer: A population based case control study. BMC Urol 2007;7:13.

[20] Daugherty SE, Pfeiffer RM, Sigurdson AJ, Hayes RB, Leitzmann M, Schatzkin A, Hollenbeck AR, Silverman DT. Nonsteroidal antiinflammatory drugs and bladder cancer: A pooled analysis. Am J Epidemiol 2011;173(7):721-30.

[21] Zhang $\mathrm{H}$, Jiang $\mathrm{D}$, Li $\mathrm{X}$. Use of nonsteroidal antiinflammatory drugs and bladder cancer risk: A metaanalysis of epidemiologic studies. PLoS One 2013; 8(7):e70008. doi: 10.1371/journal.pone.0070008.

[22] Shih C, Hotaling JM, Wright JL, White E. Long-term NSAID use and incident urothelial cell carcinoma in the VITamins and Lifestyle (VITAL) study. Urol Oncol 2013;31(8):1689-95.

[23] Baris D, Karagas MR, Koutros S, Colt JS, Johnson A, Schwenn M, Fischer AH, Figueroa JD, Berndt SI, Han S, Beane Freeman LE, Lubin JH, Cherala S, Cantor KP, Jacobs K, Chanock S, Chatterjee N, Rothman N, Silverman DT. Nonsteroidal anti-inflammatory drugs and other analgesic use and bladder cancer in northern New England. Int J Cancer 2013;132(1):162-73.

[24] Dovedi SJ, Kirby JA, Davies BR, Leung H, Kelly JD. Celecoxib has potent antitumour effects as a single agent and in combination with BCG immunotherapy in a model of urothelial cell carcinoma. Eur Urol 2008;54(3):621-30.

[25] Knapp DW, Richardson RC, Chan TC, Bottoms GD, Widmer WR, DeNicola DB, Teclaw R, Bonney PL, Kuczek T. Piroxicam therapy in 34 dogs with transitional cell carcinoma of the urinary bladder. J Vet Intern Med 1994;8(4):273-78.

[26] Knapp DW, Glickman NW, Widmer WR, DeNicola DB, Adams LG, Kuczek T, Bonney PL, DeGortari AE, Han C, Glickman LT. Cisplatin versus cisplatin combined with piroxicam in a canine model of human invasive urinary bladder cancer. Cancer Chemother Pharmacol 2000;46(3):221-26.

[27] Mohammed SI, Bennett PF, Craig BA, Glickman NW, Mutsaers AJ, Snyder PW, Widmer WR, DeGortari AE, Bonney PL, Knapp DW. Effects of the cyclooxygenase inhibitor, piroxicam, on tumor response, apoptosis, and angiogenesis in a canine model of human invasive urinary bladder cancer. Cancer Res 2002;62(2):356-58.

[28] Mohammed SI, Craig BA, Mutsaers AJ, Glickman NW, Snyder PW, deGortari AE, Schlittler DL, Coffman KT, Bonney PL, Knapp DW. Effects of the cyclooxygenase inhibitor, piroxicam, in combination with chemotherapy on tumor response, apoptosis, and angiogenesis in a canine model of human invasive urinary bladder cancer. Mol Cancer Ther $2003 ; 2(2): 183-88$.
[29] Boria PA, Glickman NW, Schmidt BR, Widmer WR, Mutsaers AJ, Adams LG, Snyder PW, DiBernardi L, de Gortari AE, Bonney PL, Knapp DW. Carboplatin and piroxicam therapy in 31 dogs with transitional cell carcinoma of the urinary bladder. Vet Comp Oncol 2005;3(2):73-80.

[30] Knapp DW, Henry CJ, Widmer WR, Tan KM, Moore GE, Ramos-Vara JA, Lucroy MD, Greenberg CB, Greene SN, Abbo AH, Hanson PD, Alva R, Bonney PL. Randomized trial of cisplatin versus firocoxib versus cisplatin/firocoxib in dogs with transitional cell carcinoma of the urinary bladder. J Vet Intern Med 2013;27(1):126-33.

[31] McMillan SK, Boria P, Moore GE, Widmer WR, Bonney PL, Knapp DW. Antitumor effects of deracoxib treatment in 26 dogs with transitional cell carcinoma of the urinary bladder. J Am Vet Med Assoc 2011;239(8):1084-89.

[32] Marconato L, Zini E, Lindner D, Suslak-Brown L, Nelson $\mathrm{V}$, Jeglum AK. Toxic effects and antitumor response of gemcitabine in combination with piroxicam treatment in dogs with transitional cell carcinoma of the urinary bladder. J Am Vet Med Assoc 2011;238(8):1004-10.

[33] Robat C, Burton J, Thamm D, Vail D. Retrospective evaluation of doxorubicin-piroxicam combination for the treatment of transitional cell carcinoma in dogs. J Small Anim Pract 2013;54(2):67-74.

[34] Allstadt SD, Rodriguez CO Jr, Boostrom B, Rebhun RB, Skorupski KA. Randomized phase III trial of piroxicam in combination with mitoxantrone or carboplatin for first-line treatment of urogenital tract transitional cell carcinoma in dogs. J Vet Intern Med 2015;29(1):261-67.

[35] Sabichi AL, Lee JJ, Grossman HB, Liu S, Richmond E, Czerniak BA, De la Cerda J, Eagle C, Viner JL, Palmer JL, Lerner SP. A randomized controlled trial of celecoxib to prevent recurrence of nonmuscle-invasive bladder cancer. Cancer Prev Res (Phila) 2011;4(10):1580-89.

[36] Pagliarulo V, Ancona P, Martines I, Spadavecchia R, Di Stasi S, Alba S, Cormio L, Fanizza C, Salerno A, Carrieri G, Pagliarulo A. Celecoxib for the prevention of nonmuscle invasive bladder cancer: Results from a matched control study. Ther Adv Urol 2015;7(6):303-11.

[37] Kurtova AV, Xiao J, Mo Q, Pazhanisamy S, Krasnow R, Lerner SP, Chen F, Roh TT, Lay E, Ho PL, Chan KS. Blocking PGE2-induced tumour repopulation abrogates bladder cancer chemoresistance. Nature 2015;517(7533):209-13.

[38] Dhawan D, Craig BA, Cheng L, Snyder PW, Mohammed SI, Stewart JC, Zheng R, Loman RA, Foster RS, Knapp DW. Effects of short-term celecoxib treatment in patients with invasive transitional cell carcinoma of the urinary bladder. Mol Cancer Ther 2010;9(5):1371-77.

[39] Kim MS, Kim JE, Lim do Y, Huang Z, Chen H, Langfald A, Lubet RA, Grubbs CJ, Dong Z, Bode AM. Naproxen induces cell-cycle arrest and apoptosis in human urinary bladder cancer cell lines and chemically induced cancers by targeting PI3K. Cancer Prev Res (Phila) 2014;7(2):236-45.

[40] Samadi AK, Bilsland A, Georgakilas AG, Amedei A, Amin A, Bishayee A, Azmi AS, Lokeshwar BL, Grue B, Panis C, Boosani CS, Poudyal D, Stafforini DM, Bhakta D, Niccolai E, Guha G, Vasantha Rupasinghe HP, Fujii H, Honoki K, Mehta K, Aquilano K, Lowe L, Hofseth LJ, Ricciardiello L, Ciriolo MR, Singh N, Whelan RL, Chaturvedi R, Ashraf SS, Shantha Kumara HM, Nowsheen S, Mohammed SI, Keith WN, Helferich WG, Yang X. A multi-targeted approach to suppress tumor-promoting inflammation. Semin Cancer Biol 2015;35(Suppl:S1):51-84.

[41] Bu Q, Fang Y, Cao Y, Chen Q, Liu Y. Enforced expression of miR-101 enhances cisplatin sensitivity in human bladder 
cancer cells by modulating the cyclooxygenase- 2 pathway. Mol Med Rep 2014;10(4):2203-09.

[42] Knapp DW, Ramos-Vara JA, Moore GE, Dhawan D, Bonney PL, Young KE. Urinary bladder cancer in dogs, a naturally occurring model for cancer biology and drug development. ILAR J 2014;55(1):100-18.

[43] Arnold EJ, Childress MO, Fourez LM, Tan KM, Stewart JC, Bonney PL, Knapp DW. Clinical trial of vinblastine in dogs with transitional cell carcinoma of the urinary bladder. J Vet Intern Med 2011;25(6):1385-90.

[44] Blumenreich MS, Yagoda A, Natale RB, Watson RC. Phase II trial of vinblastine sulfate for metastatic urothelial tract tumors. Cancer 1982;50(3):435-38.

[45] André N, Abed S, Orbach D, Alla CA, Padovani L, Pasquier E, Gentet JC, Verschuur A. Pilot study of a pediatric metronomic 4-drug regimen. Oncotarget 2011;2(12): 960-65.

[46] Young SD, Whissell M, Noble JC, Cano PO, Lopez PG, Germond CJ. Phase II clinical trial results involving treatment with low-dose daily oral cyclophosphamide, weekly vinblastine, and rofecoxib in patients with advanced solid tumors. Clin Cancer Res 2006;12(10):3092-98.

[47] Dhawan D, Ramos-Vara JA, Naughton JF, Cheng L, Low PS, Rothenbuhler R, Leamon CP, Parker N, Klein PJ, Vlahov IR, Reddy JA, Koch M, Murphy L, Fourez LM, Stewart JC, Knapp DW. Targeting folate receptors to treat invasive urinary bladder cancer. Cancer Res 2013;73(2):875-84.

[48] Owen LN. TNM Classification of Tumours in Domestic Animals. 1st ed. Geneva: World Health Organization; 1980.

[49] Arrington KA, Legendre AM, Tabeling GS, Frazier DL. Comparison of body surface area-based and weight-based dosage protocols for doxorubicin administration in dogs. Am J Vet Res 1994;55(11):1587-92.

[50] Veterinary cooperative oncology group - common terminology criteria for adverse events (VCOG-CTCAE) following chemotherapy or biological antineoplastic therapy in dogs and cats v1.1. Vet Comp Oncol. 2011 Jul 20.

[51] Nguyen SM, Thamm DH, Vail DM, London CA. Response evaluation criteria for solid tumours in dogs (v1.0): Cooperative Oncology Group (VCOG) consensus document. Vet Comp Oncol 2015;13(3):176-83.

[52] Shapiro SG, Raghunath S, Williams C, Motsinger-Reif AA, Cullen JM, Liu T, Albertson D, Ruvolo M, Bergstrom Lucas A, Jin J, Knapp DW, Schiffman JD, Breen M. Canine urothelial carcinoma: Genomically aberrant and comparatively relevant. Chromosome Res 2015;23(2):311-31.

[53] Dhawan D, Paoloni M, Shukradas S, Choudhury DR, Craig BA, Ramos-Vara JA, Hahn N, Bonney PL, Khanna C, Knapp DW. Comparative gene expression analyses identify luminal and basal subtypes of canine invasive urothelial carcinoma that mimic patterns in human invasive bladder cancer. PLoS One 2015;10(9):e0136688.

[54] Decker B, Parker HG, Dhawan D, Kwon EM, Karlins E, Davis BW, Ramos-Vara JA, Bonney PL, McNiel EA, Knapp DW, Ostrander EA. Homologous mutation to human BRAF V600E is common in naturally occurring canine bladder cancer-evidence for a relevant model system and urine-based diagnostic test. Mol Cancer Res 2015;13(6):993-1002.

[55] Mochizuki H, Kennedy K, Shapiro SG, Breen M. BRAF mutations in canine cancers. PLoS One 2015; 10(6):e0129534.

[56] Hall RD1, Kudchadkar RR. BRAF mutations: Signaling, epidemiology, and clinical experience in multiple malignancies. Cancer Control 2014;21(3):221-30.
[57] Cancer Genome Atlas Research Network. Comprehensive molecular characterization of urothelial bladder carcinoma. Nature 2014;507(7492):315-22.

[58] Dharmapuri G, Doneti R, Philip GH, Kalle AM. Celecoxib sensitizes imatinib-resistant K562 cells to imatinib by inhibiting MRP1-5, ABCA2 and ABCG2 transporters via Wnt and Ras signaling pathways. Leuk Res 2015;39(7):696701.

[59] Chen Q, Chong T, Yin J, Luo P, Deng A. Molecular events are associated with resistance to vinblastine in bladder cancer. Cell Mol Biol (Noisy-le-grand) 2015;61(2):33-38.

[60] Mohammed SI, Dhawan D, Abraham S, Snyder PW, Waters DJ, Craig BA, Lu M, Wu L, Zheng R, Stewart J, Knapp DW. Cyclooxygenase inhibitors in urinary bladder cancer: in vitro and in vivo effects. Mol Cancer Ther 2006;5(2):32936.

[61] Alme AK, Karir BS, Faltas BM, Drake CG. Blocking immune checkpoints in prostate, kidney, and urothelial cancer: An overview. Urol Oncol 2016.01.006. [Epub ahead of print].

[62] Liu B, Qu L, Yan S. Cyclooxygenase-2 promotes tumor growth and suppresses tumor immunity. Cancer Cell Int 2015;15:106.

[63] Zelenay S, van der Veen AG, Böttcher JP, Snelgrove KJ, Rogers N, Acton SE, Chakravarty P, Girotti MR, Marais R, Quezada SA, Sahai E, Reis e Sousa C. CyclooxygenaseDependent Tumor Growth through Evasion of Immunity. Cell 2015;162(6):1257-70.

[64] Xu P, Sun Z, Wang Y, Miao C. Long-term use of indomethacin leads to poor prognoses through promoting the expression of PD-1 and PD-L2 via TRIF/NF-кB pathway and JAK/STAT3 pathway to inhibit TNF- $\alpha$ and IFN- $\gamma$ in hepatocellular carcinoma. Exp Cell Res 2015;337(1): 53-60.

[65] Dhawan D, Jeffreys AB, Zheng R, Stewart JC, Knapp DW. Cyclooxygenase-2 dependent and independent antitumor effects induced by celecoxib in urinary bladder cancer cells. Mol Cancer Ther 2008;7(4):897-904.

[66] Liggett JL, Zhang X, Eling TE, Baek SJ. Anti-tumor activity of non-steroidal anti-inflammatory drugs: Cyclooxygenaseindependent targets. Cancer Lett 2014;346(2):217-24.

[67] Campione E, Paternò EJ, Candi E, Falconi M, Costanza G, Diluvio L, Terrinoni A, Bianchi L, Orlandi A. The relevance of piroxicam for the prevention and treatment of nonmelanoma skin cancer and its precursors. Drug Des Devel Ther 2015;9:5843-50.

[68] Gurpinar E, Grizzle WE, Piazza GA COX-independent mechanisms of cancer chemoprevention by antiinflammatory drugs. Front Oncol 2013;3:181.

[69] Sinha M, Gautam L, Shukla PK, Kaur P, Sharma S, Singh TP. Current perspectives in NSAID-induced gastropathy. Mediators Inflamm 2013;2013:258209.

[70] Solomon SD, Wittes J, Finn PV, Fowler R, Viner J, Bertagnolli MM, Arber N, Levin B, Meinert CL, Martin B, Pater JL, Goss PE, Lance P, Obara S, Chew EY, Kim J, Arndt G, Hawk E; Cross Trial Safety Assessment Group. Cardiovascular risk of celecoxib in 6 randomized placebo controlled trials: The cross trial safety analysis. Circulation 2008;117:2104-13.

[71] Bavry AA, Thomas F, Allison M, Johnson KC, Howard BV, Hlatky M, Manson JE, Limacher MC. Nonsteroidal anti-inflammatory drugs and cardiovascular outcomes in women: Results from the women's health initiative. Circ Cardiovasc Qual Outcomes 2014;7(4):603-10. 